\title{
TREE-RING ANOMALIES IN TOONA CILIATA
}

\author{
Ingo Heinrich ${ }^{1,2}$ and John Charles Gripper Banks ${ }^{1}$
}

\begin{abstract}
SUMMARY
New increment core samples of Toona ciliata collected in the Australian tropics and subtropics compared to already existing material from the Upper Kangaroo Valley, near Sydney exhibit distinct differences in tree-ring structures. This necessitated a closer examination of the wood anatomy, possible false rings and the species' crossdating capacity in northeast Australia. During tree-ring analysis two growth anomalies (extensive zones of narrow and indistinct rings) and three types of false rings were discovered which complicated crossdating. However, in growth experiments only one type of false ring could be induced artificially by totally defoliating young trees. It was possible to alter their phenological performance by artificially changing the environmental conditions. Visual crossdating of samples originating from northeast Australia was feasible within and between trees. For selected years a positive relationship between ring width and precipitation data was found.
\end{abstract}

Key words: Australian red cedar, false ring, growth experiment, intraseasonal pinning, crossdating.

\section{INTRODUCTION}

Tree rings are identifiable structural changes within the wood, which usually appear as bands of different colours and shades to the naked eye. However, initial dendrochronological research of 'new' species must always be aware of possible false or missing rings, especially in the tropics where true dormancy and hence annual tree rings are rather an exception due to the weaker seasonality of the climate.

In mainland Australia tree-ring records are notoriously lacking although long-term climatic proxies are needed to improve the reliability of the seasonal forecast models computed by the national weather service. Dendrometer band data and increment core samples of Toona ciliata demonstrated for the first time the dendroclimatological potential of the species. It was ascertained that at the southern limit of its natural distribution near Sydney the species is easily crossdatable because it does not exhibit false or otherwise indistinct rings (Heinrich \& Banks 2005). Through repetitive intraseasonal sampling it was shown that Toona ciliata has three diagnostic features for the

1) School of Resources, Environment \& Society, Australian National University, Canberra, ACT 0200, Australia.

2) Present address: Department of Geosciences, Geography, University of Fribourg, 1700 Fribourg, Switzerland [E-mail: ingo.heinrich@unifr.ch]. 
identification of a typical tree-ring boundary, i.e., firstly a line of initial parenchyma cells, secondly an abrupt shift from few small latewood vessels to a line of many large earlywood vessels and thirdly a change from thick-walled latewood fibre cells with small lumen to thin-walled earlywood fibres with large lumen.

However, preliminary examination of further $T$. ciliata samples recently collected at additional subtropical to tropical sites in northeast Australia has revealed difficult tree-ring structures potentially complicating crossdating procedures. A comparison of two examples collected in Lamington National Park (montane tropical rainforest, Queensland) and Upper Kangaroo Valley (lowland subtropical to temperate rainforest, near Sydney) illustrates the general wood anatomical differences, e.g., ring width and vessel size (Fig. 1).
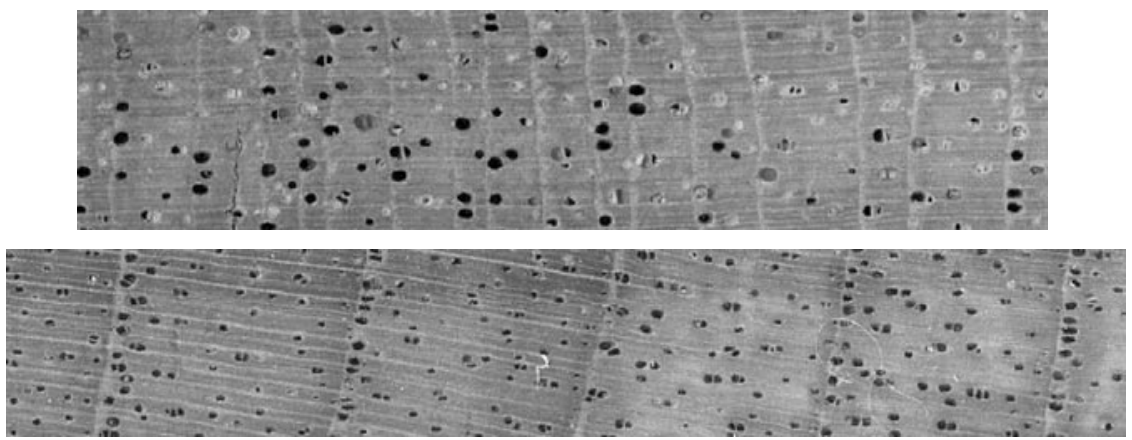

Fig. 1. Typical growth rings of Toona ciliata in Lamington National Park (top) and Upper Kangaroo Valley (bottom).

Furthermore, several studies already reported the possibility of false rings in Toona ciliata and related species (Coster 1928; Amobi 1974; Bhattacharyya et al. 1992). In a comprehensive study Coster (1928) was able to induce false tree rings artificially by defoliating, shading, or applying a minimum water treatment to various tropical tree species. The defoliation experiment was divided into two parts: total and partial defoliation. The first group of trees showed an extra tree ring consisting of a zone of vessels that did not change in size compared to the vessels before defoliation. The vessels were not embedded in initial parenchyma cells, as they usually are in Toona ciliata M. Roem., nor were there any recognisable changes in the fibre cell sizes. The second group showed similar effects, that is, no change in the sizes of the fibre cells, and no initial parenchyma cells were present. A ring of vessels had also been formed but these were less distinct than those in the first group and even less in the lower part of the stem, where the impact of the defoliation seemed to exert a decreasing influence. The increment growth of the first group lagged behind that of the second because growth was probably altered more severely by total defoliation.

Coster (1928) also conducted shading experiments with Tectona grandis L.f. and Melia azedarach L. The trees were kept in dark chambers until they lost their leaves, either partially or totally. Both species produced an extra growth zone marked first by 
a zone of cells with thin walls and filled with starch followed by a ring of smaller but numerous vessels.

In the last part of his experiment, Coster (1928) did not water seedlings of Melia azedarach for two weeks which resulted in total defoliation and destruction of the leading shoot. After being watered again the trees started flushing new leaves. As in the previous experiments, a false ring was formed, easily identifiable by a lack of parenchyma cells and unchanged vessel sizes.

Bhattacharyya et al. (1992) analysed the dendroclimatological potential of four tropical species in India, among them Cedrela toona, which now is Toona ciliata. They collected ten cores from eight trees growing in an evergreen forest. After the standard dendrochronology treatment they found ring- to semi-ring porous structures with clear growth rings delimited by large pores and initial parenchyma. They identified false rings as lines of concentric parenchymatous cells within earlywood cells similar to the initial parenchyma but without a marked change in vessel size as usually occurred at the ring boundary. They did not find any absent rings.

Amobi (1974) observed four clear growth rings in a four-year-old branch of Hildegardia barteri (Mast.) Kosterm., although lateral twigs were formed intra-seasonally. He concluded that their formation had not led to the induction of multiple growth rings because they appeared when active radial growth was in progress and hormone levels responsible for forming large earlywood vessels were already high, hence no additional rings were formed.

During the tropical wet season, generally, and a cyclone in particular (Webb 1958; Unwin et al. 1988), low light levels in a forest can become limiting to a plant's metabolism. Low solar radiation conditions have the potential to force plants into a negative energy balance due to low assimilation and high dissimilation rates. For example, when cyclone Rona crossed the northeast Australian coast in mid-February 1999 measurements of photosynthetic active radiation (PAR) at Daintree National Park dropped to 250 $\mu \mathrm{mol} / \mathrm{m} / \mathrm{s}$ PAR compared to a maximum value of approximately $2400 \mu \mathrm{mol} / \mathrm{m} / \mathrm{s}$ PAR (data kindly provided by Prof. Dr. Steve Turton, James Cook University, Cairns).

Gopikumur and Bindu (1999) studied the effects of shade on the growth of Toona ciliata seedlings in India by exposing them to $50 \%$ shade. It was recorded that, compared to the plants growing in the open, the shaded trees showed more height and less radial increment growth, but possible effects on tree-ring structures were not reported. Doley (1979) investigated the effects of shade on xylem development in Eucalyptus grandis Hill ex Maiden. In low light, the rate of cambial cell division was slower than in high light conditions, and the rate of wall thickening was much lower in the low light treatment.

False rings in Toona ciliata and related species have been reported in several studies but have not been presented visually yet. Hence, before successful dendroclimatological research on $T$. ciliata derived from tropical to subtropical regions can be conducted, a wood anatomical analysis of the new samples is necessary to gain more confidence for further tree-ring analysis. In this paper we first demonstrate visually the wood anatomical anomalies, then present results of a growth experiment trying to induce false rings and finally show examples of visual crossdating within and between trees. 


\section{MATERIALS AND METHODS}

Increment core sampling, preparation and analysis

Standard dendrochronology methods were applied in the current study (Stokes \& Smiley 1968; Fritts 1976; Schweingruber 1983; Cook \& Kairiukstis 1990). In addition to the existing data set from Kangaroo Valley (Heinrich \& Banks 2005) dominant to subdominant trees were sampled in Eungella National Park (lat. $21^{\circ} 02^{\prime} \mathrm{S} /$ lon. $148^{\circ}$ $37^{\prime}$ E, $700 \mathrm{~m}$ asl), Lamington National Park (lat. $28^{\circ} 15^{\prime} \mathrm{S} /$ lon. $153^{\circ} 08^{\prime}, 800 \mathrm{~m}$ asl) and Atherton Tablelands (lat. $17^{\circ} 30^{\prime} \mathrm{S} / \mathrm{lon} .145^{\circ} 58^{\prime} \mathrm{E}, 720 \mathrm{~m}$ asl). The sites are located within the natural distribution of the species in mature complex notophyll vine rainforest (CNVF) of the cooler uplands (Webb 1959). The surfaces of the core samples were treated according to routine sample preparations (Bowers 1964; Pilcher 1990). The smooth surface of the cores allowed them to be scanned in high resolution mode and imported to digital imagery software. Crossdating of the new material was conducted and will be demonstrated visually. However, several false rings and difficult tree-ring boundary zones were encountered during crossdating and are presented before. Growth experiments were carried out to improve understanding of these wood anatomical peculiarities and variations.

\section{Growth experiment}

The growth experiment, conducted from January 2001 to January 2002, attempted to stimulate development of false tree rings in two-year-old Toona ciliata seedlings. The experiment includes one control group and three treatment groups with four specimens each. All trees were kept in glasshouses with automatically regulated temperature and received an optimum supply of nutrients by applying slow-release fertilizer tablets Scout Osmocote (Nitrogen 18\%, Phosphorus 4.8\% and Potassium 9.1\%). The plants in control group A were watered at least every day, in summer two to three times a day. Most of the time group B was treated exactly like group A, but in the middle of the growing period (mid-February 2001) the plants were not watered for eleven days. The previous watering schedule was resumed after distinct signs of leaf wilting indicated realistic imitation of natural drought conditions. In group $\mathrm{C}$ trees were defoliated manually in the middle of their active growth period. This treatment was designed to imitate natural loss of foliage occurring due to insect attack or cyclone damage. In group D specimens were kept under very low light conditions, that is, $200 \mu \mathrm{mol} / \mathrm{m} / \mathrm{s}$ compared to $2300 \mu \mathrm{mol} / \mathrm{m} / \mathrm{s}$ PAR on a sunny day in Canberra. This experiment was designed to reproduce a typical wet-season situation in the wet tropics during a major monsoonal depression or cyclone. During such situations a thick cloud cover along with hot and humid conditions prevails for an extended period of time.

\section{The pinning method}

The pinning method was first employed and described by Mariaux (1967) and Wolter (1968). They found that an injury of the cambium resulted in the formation of aberrant parenchymatous-like cells that were permanently retained, recognisable and datable within the growth zone. The various pinning methods using needles, nails or knives in order to wound the cambium were discussed in Sass et al. (1995). Kuroda and 
Shimaji (1984) demonstrated for the first time that the pinning method also works for hardwoods on an intra-seasonal timescale. Subsequent studies supported their findings (Kuroda and Shimaji 1985; Kuroda 1986; Shiokura 1989; Nobuchi et al. 1995; Fujii et al. 1999; Bauch \& Dünisch 2000).

During the experiment quarterly pinning was conducted from four cardinal points. Initial measurements of the height and diameter of the plants were taken and repeated every quarter parallel to the application of the pinning. The phenology and general condition of the plants were recorded weekly. On 29 January 2002 the experiment was terminated by crosscutting the stems close to the different pinning areas, and the samples were stored and prepared for further microscopic examination.

\section{Preparation of samples for microscopy and digital imagery}

For further microscopic analysis, thin transverse sections were cut using a technique invented by Heady (1997) as a preparation technique for scanning electron microscopy. The technique makes use of a small vice which can be installed under the lens of a microscope to hold small samples. This allows the user to cut thin sections with both hands while observing the actions under magnification. As a result more sections were cut than would have been possible with a microtome. Since the observations were limited to tree-ring structure observations in low magnification the disadvantage of this technique (thicker sections limiting visibility) were accepted. Digital photos of the pinning wounds and surrounding tissues were taken with a Zeiss Axioskop equipped with a digital camera and then imported to the digital imagery software ImageJ (supplied by the National Institutes of Health, USA at http://rsb.info.nih.gov/ij/index.html). The samples were examined for possible true and false tree rings formed during the experiment.

\section{RESULTS}

\section{Tree-ring anomalies}

The first potential problem occurred when tree rings were too narrow to ensure reliable identification and measurement of individual rings (Fig. 2). Such narrow rings seemed to lack latewood completely and to consist of large vessels embedded in parenchymatous tissue visible here as black holes separated by light vertical lines. Apart

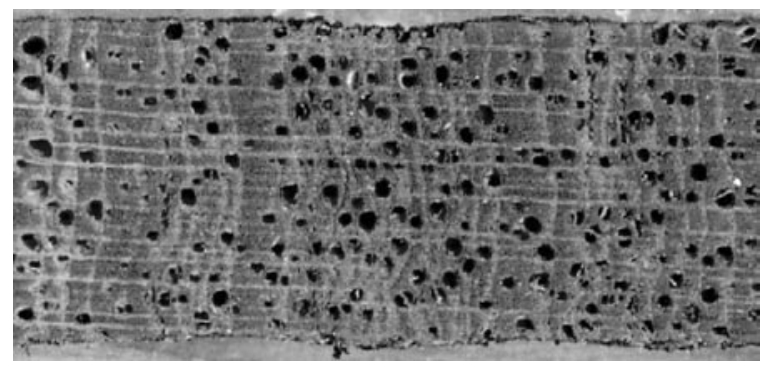

Fig. 2. Sample 10a from Eungella National Park exhibiting narrow rings. 
from being difficult to separate for individual measurements, these zones of numerous narrow rings exhibit much less variability than in normal growth zones and they can occur anywhere within the wood and extend for many rings. The growth change from average-sized to very narrow rings and vice versa is often quite sharp.

Poor climatic conditions for several years may result in the formation of an interval with very narrow rings; such intervals can be used as pointer years but zones of numerous successive narrow rings are very likely not caused by climate but more likely by other factors, for example, competition or senescence within a forest stand. Furthermore, Banks (1993) observed that tree rings formed by senescing eucalypts may be narrower than the width of individual vessels. Consequently, tree-ring widths were distorted by vessels incorporating ring-width variation unrelated to climate. This noise hindered crossdating and reduced the resulting length of eucalypt tree-ring series measured from the oldest specimens. Similar problems can occur in samples of T. ciliata and hence these zones of many narrow rings hold a high potential to complicate the subsequent dendroclimatological analysis.

A second problem was encountered when tree rings were too indistinct for a sound identification of the early- to latewood boundary. The indistinctness of the ring structure is explained by a total lack of tree-ring characteristics such as parenchyma bands or seasonal alternations between large and small vessels (Fig. 3).

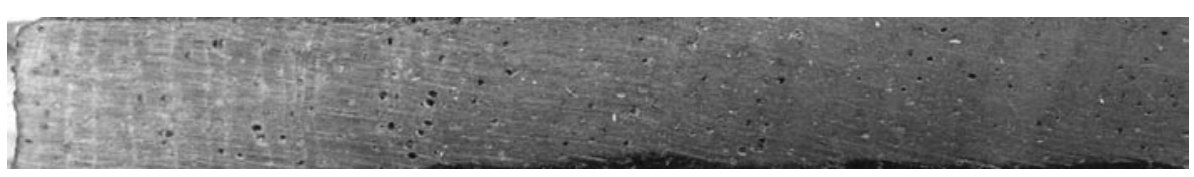

Fig. 3. Sample 69a from Gillis Range (Atherton Tablelands) with indistinct ring patterns, especially in the darker part of the wood.

Many tree species in the tropics sometimes produce false rings which are not annual but might occur due to an intra-annual event, for example, when a tree is forced into cambial dormancy after several weeks without any precipitation. If wetter conditions return during the same season, trees often resume their cambial growth. The anatomical result of such a hypothetical event can be seen in Figure 4 which consists of a macroscopic image on top with the microscopic images below showing in more detail true ring boundaries and an intra-annual density fluctuation between them. The density fluctuation differs from a true ring boundary because no change in vessel diameter size is detectable and initial parenchyma is lacking.

A second false ring type is presented in Figure 5: the arrows indicate ring zones that show two out of three diagnostic tree-ring features. These false rings exhibit a distinct change of fibre cell properties visible macroscopically as a zone of dark colour changing into a lighter tone with a line of tangential parenchyma between them. But only a few vessels are present along this line and they do not change in size in comparison to the vessels formed just before. 

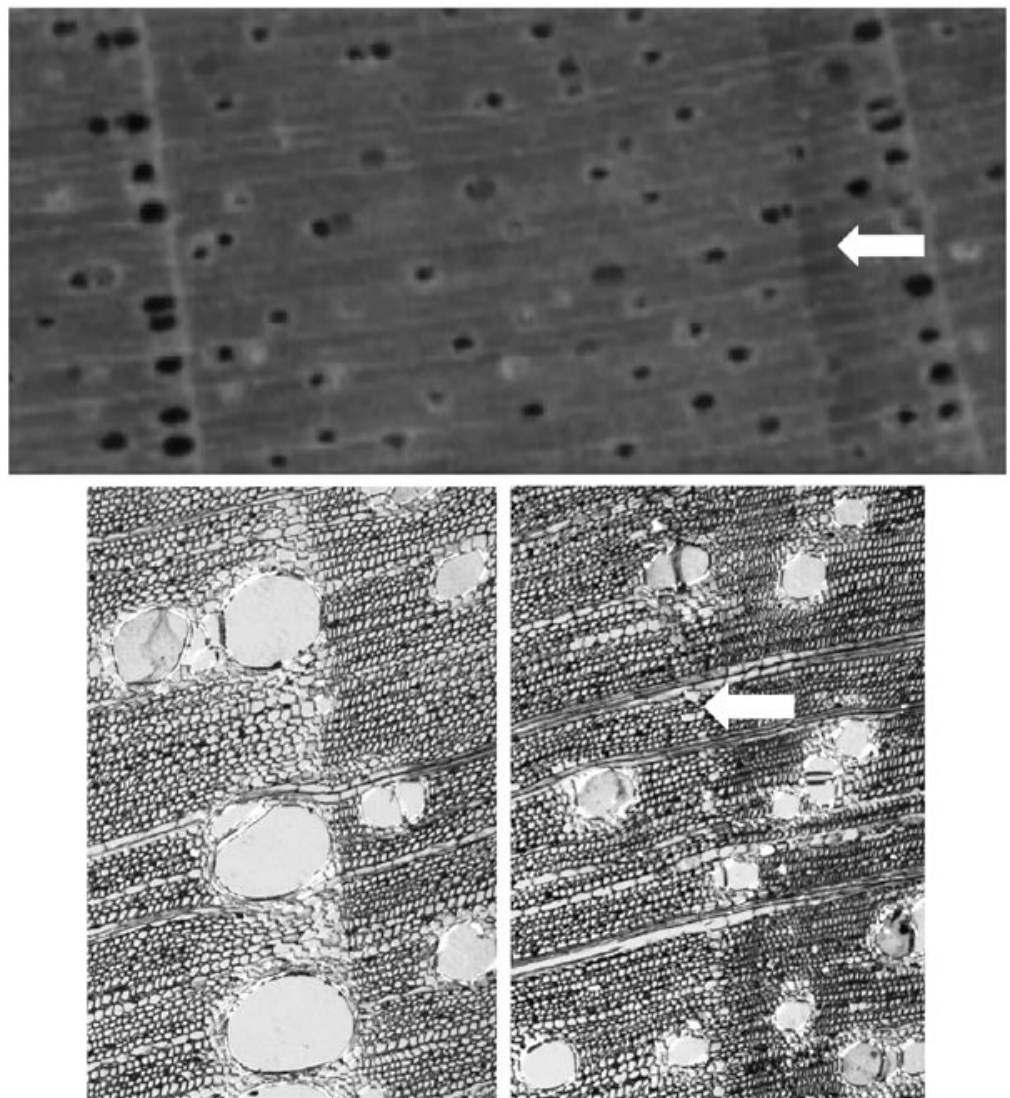

Fig. 4. Combination of macroscopic (top) and microscopic samples (bottom) $(\times 50)$ illustrating a true ring boundary (left) and a false ring boundary (right).
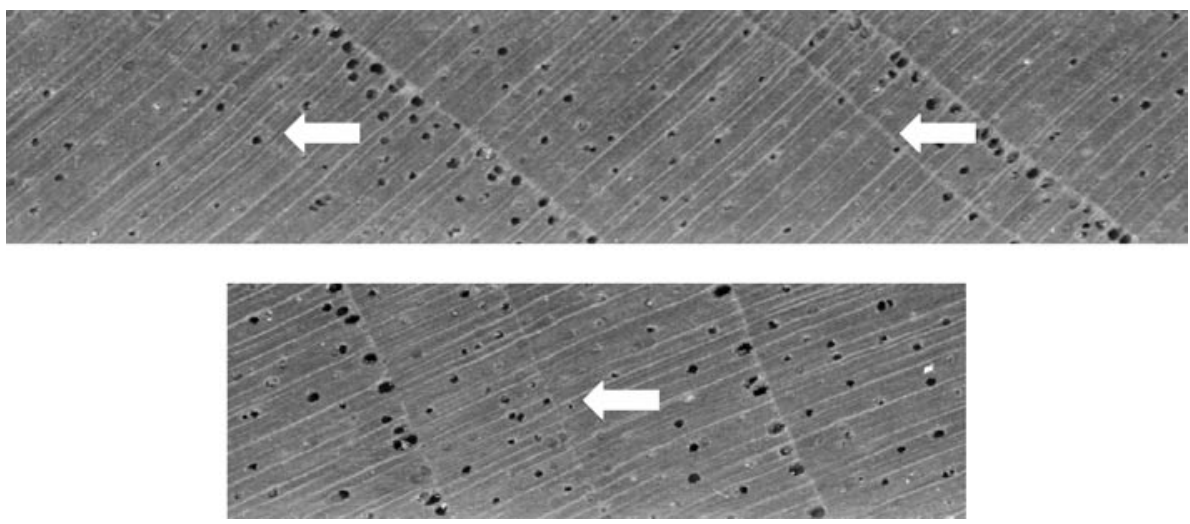

Fig. 5. Sample 121b illustrating true and false ring boundaries. 


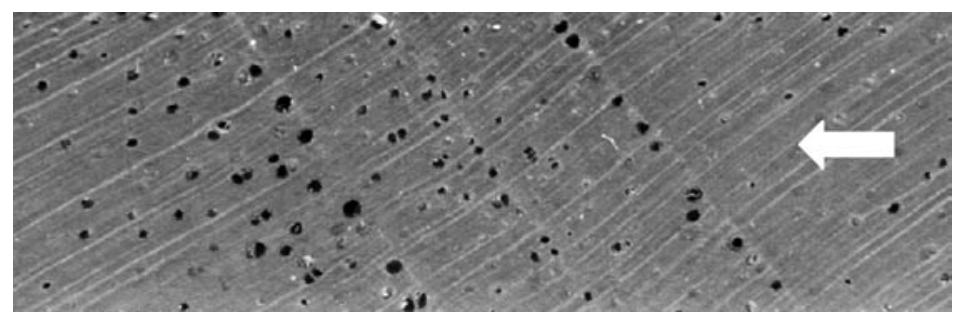

Fig. 6. Sample 84a showing true and false ring boundaries.

A third version of a possible false ring is shown in Figure 6: the arrow points to a line of parenchyma cells with several small vessels arranged along them. This potentially false boundary is less distinct than the adjacent boundaries because the vessel size and the ratio fibre cell wall to lumen, hence the colour of the wood, do not change markedly.

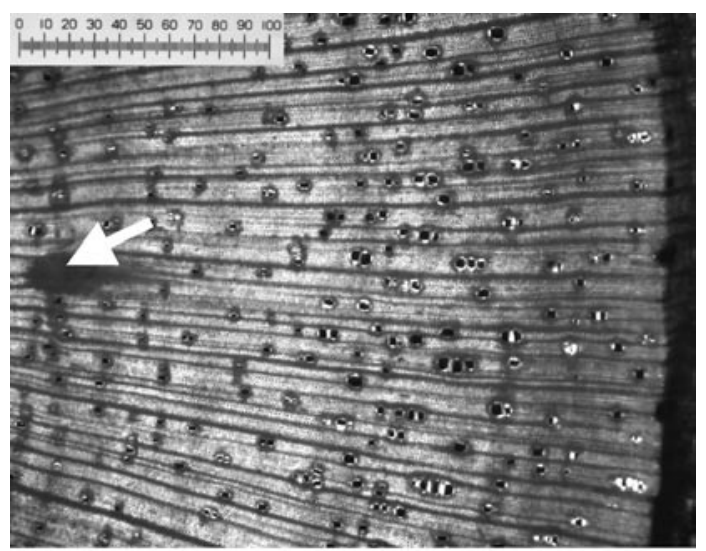

Fig. 7. No false rings visible in control trees 25 and 26 (bark tissue on right, pith on left, wound tissue indicated by arrows). Scale: 100 units $=1 \mathrm{~mm}$.

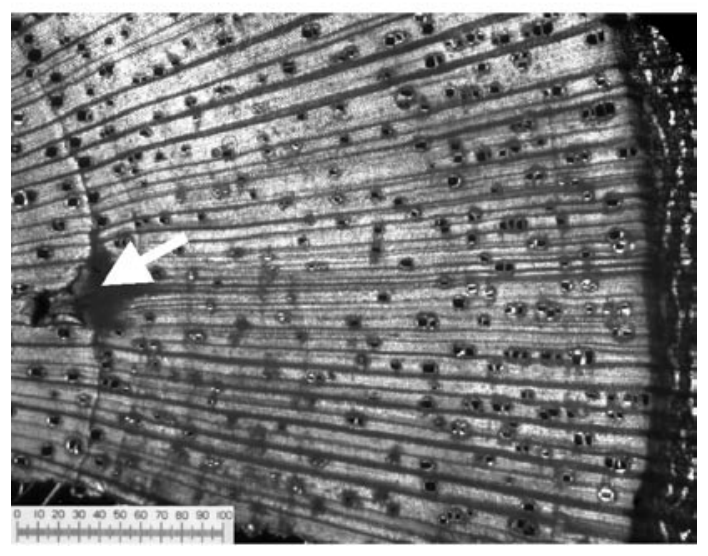

\section{Growth experiment}

Trees of optimum group A did not become deciduous and hence their cambium probably did not enter dormancy. Two samples of trees from group A (Fig. 7) illustrate that after the initial pinning no tree-ring boundary was formed but instead wood formation was continued throughout the one-year experiment resulting in large diameter increments. 
Fig. 8. No formation of false rings in trees 29 and 30 , group B (bark tissue on right, pith on left, wound tissue of the pinning applied just before the non-water treatment, indicated by arrows). Scale: 100 units $=1 \mathrm{~mm}$.

The temporary no-water treatment in group $\mathrm{B}$ which lasted for eleven days did not result in false rings (Fig. 8). The seedlings exhibited strong signs of wilting and lost some leaves but recovered swiftly and replaced the incomplete foliage. Growth increments were smaller in group B compared to trees in group A.

After their defoliation all trees of group $\mathrm{C}$ showed rapid recovery, i.e., within two to four days new leaves started to develop and after one month the foliage was fully restored. The example images in Figure 9 show that the defoliation experiment was successful in creating false rings. The trees exhibit a false ring immediately after the application of the pinning. These false rings consist of lines of parenchyma and several vessels with no size changes. During the same period the control trees produced new leaves as well as part of their natural phenological behaviour. However, they did not form a false ring boundary near the wound tissue (compare Fig. 7).

Fig. 9. Formation of false rings (indicated by small arrows) due to defoliation of trees 50 (top), 51 (bottom) (bark tissue on the right, pith on the left, wound tissue indicated by big arrows). Scale: 100 units $=1 \mathrm{~mm}$.
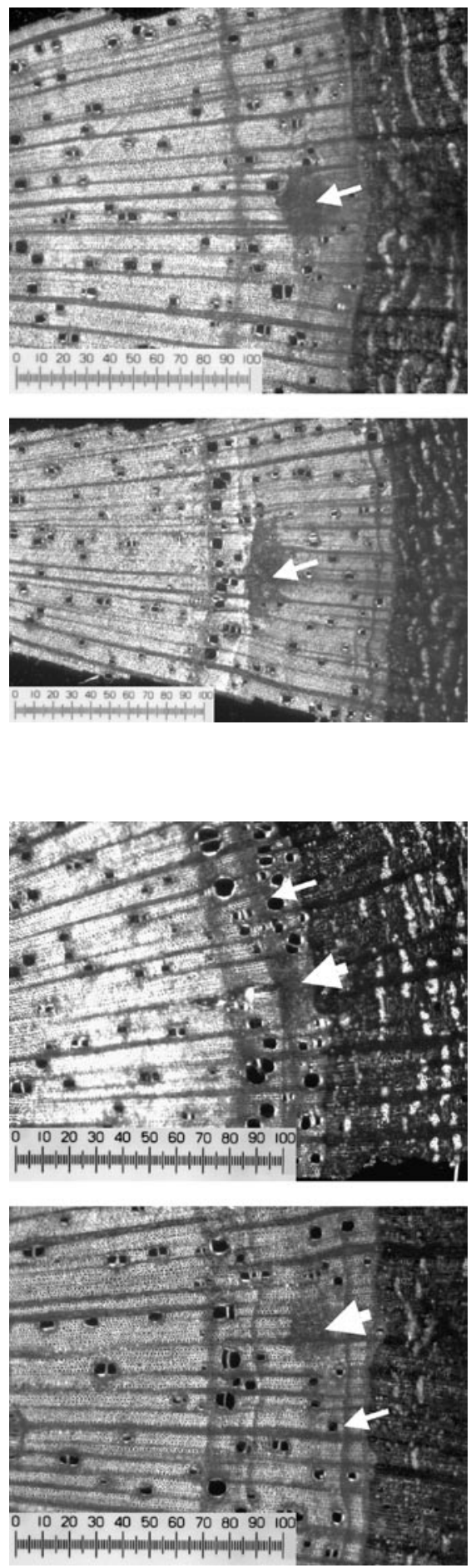
Fig. 10. No formation of false ring in trees 58 (top) and 59 (bottom) during a shading experiment (bark tissue on the right, pith on the left, wound tissue indicated by arrows). Scale: 100 units $=$ $1 \mathrm{~mm}$.

In group $\mathrm{D}$, trees were placed under shade cloth, and within a few days into the experiment all trees produced new leaves and maintained the formation of new leaves for months afterwards. The trees did not enter a leafless or semi-leafless period, and false rings were not formed (Fig. 10) but a distinct reduction in diameter

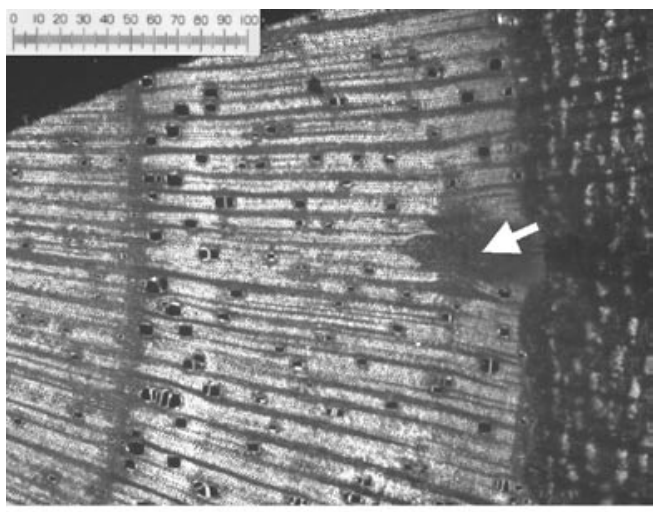
growth occurred.

The growth increments for height and diameter expressed as percentages are $33.78 \%$ and $5.26 \%$, respectively. The equivalent growth increments for the control specimens are $38.18 \%$ in tree height and $60.68 \%$ in diameter (Table 1). The comparison of the shaded trees and the control trees indicates that during an extended period of low-light conditions young specimens of Toona ciliata are likely to decrease diameter growth noticeably while keeping up similar levels of height increments at the same time.

Table 1. Average increases in stem height and diameter in group A, optimum group and group D, shading group.

\begin{tabular}{|l|cc|cc|}
\hline \multirow{2}{*}{ Date } & \multicolumn{2}{|c|}{ Group A } & \multicolumn{2}{c|}{ Group D } \\
\cline { 2 - 5 } & Height $(\mathrm{cm})$ & Diameter $(\mathrm{mm})$ & Height $(\mathrm{cm})$ & Diameter $(\mathrm{mm})$ \\
\hline Jan-01 & 98.3 & 7.9 & 91.8 & 16.6 \\
Jan-02 & 214.5 & 20.7 & 140.5 & 17.6 \\
Total & 116.3 & 12.8 & 48.8 & 1.0 \\
Percentage & $\mathbf{3 8 . 2}$ & $\mathbf{6 0 . 7}$ & $\mathbf{3 3 . 8}$ & $\mathbf{5 . 3}$ \\
\hline
\end{tabular}



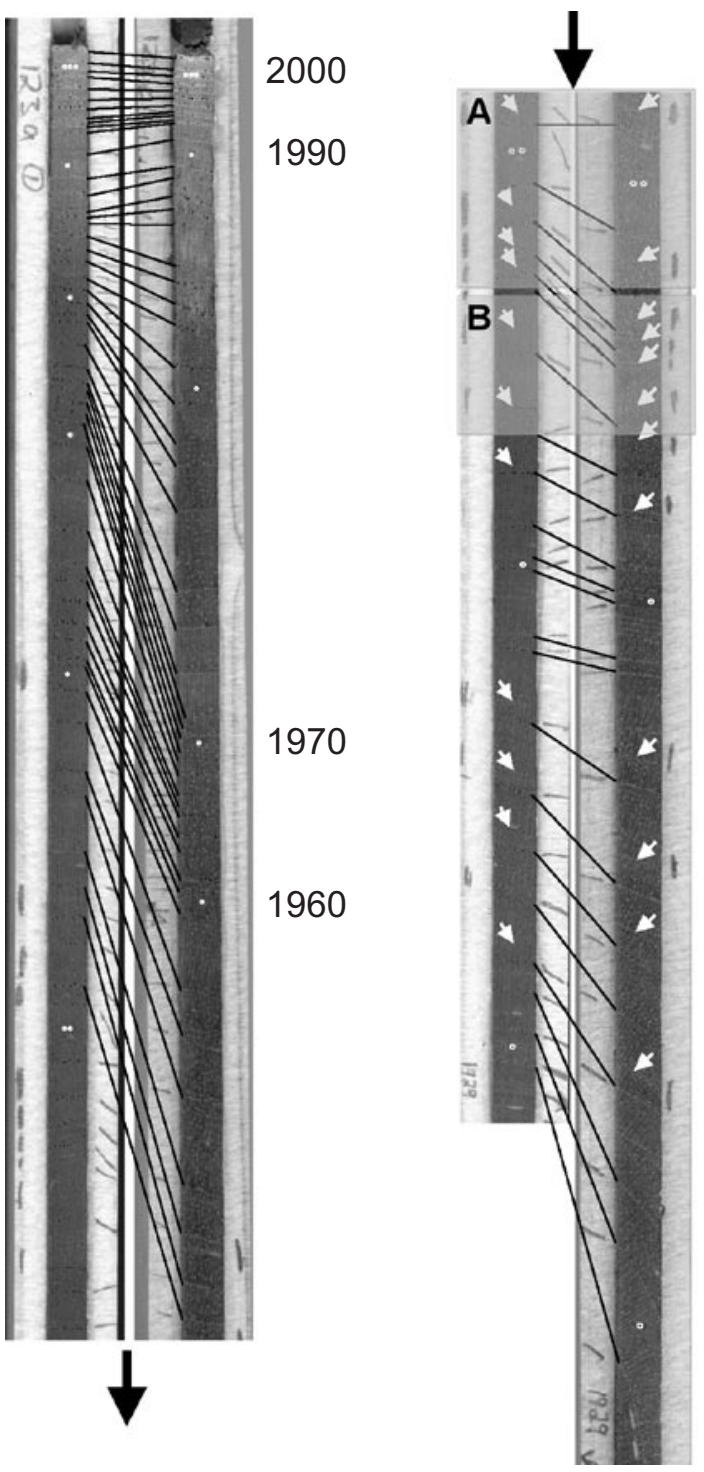

1950

1940

Fig. 11. Crossdating of samples 123a (left) and 123b (right); lines connect corresponding years; white arrows indicate density fluctuations and false rings; boxes $\mathrm{A}$ and $\mathrm{B}$ are shown in more detail in Figures 12 and 13.

\section{Visual crossdating}

It has been demonstrated that Toona ciliata growing under tropical to subtropical conditions forms difficult growth zones and false rings potentially complicating crossdating procedures. Nevertheless, the following visual analysis shows that crossdating is possible despite these problems. The successful crossdating of two core samples collected from one tree is illustrated in Figures 11 to 13. Figure 11 provides an overview of the two samples which were cut in halves with the younger parts positioned on the left and the older on the right to fit in one image. The chronological sequence is indicated by 
black arrows and individual years are connected by lines for better comparability. Additionally, white arrows indicate density fluctuations and false rings that have been identified and deleted during analysis. The boxes A and B mark two areas that are magnified and presented in Figures 12 and 13 in order to show details of false rings deleted during crossdating.

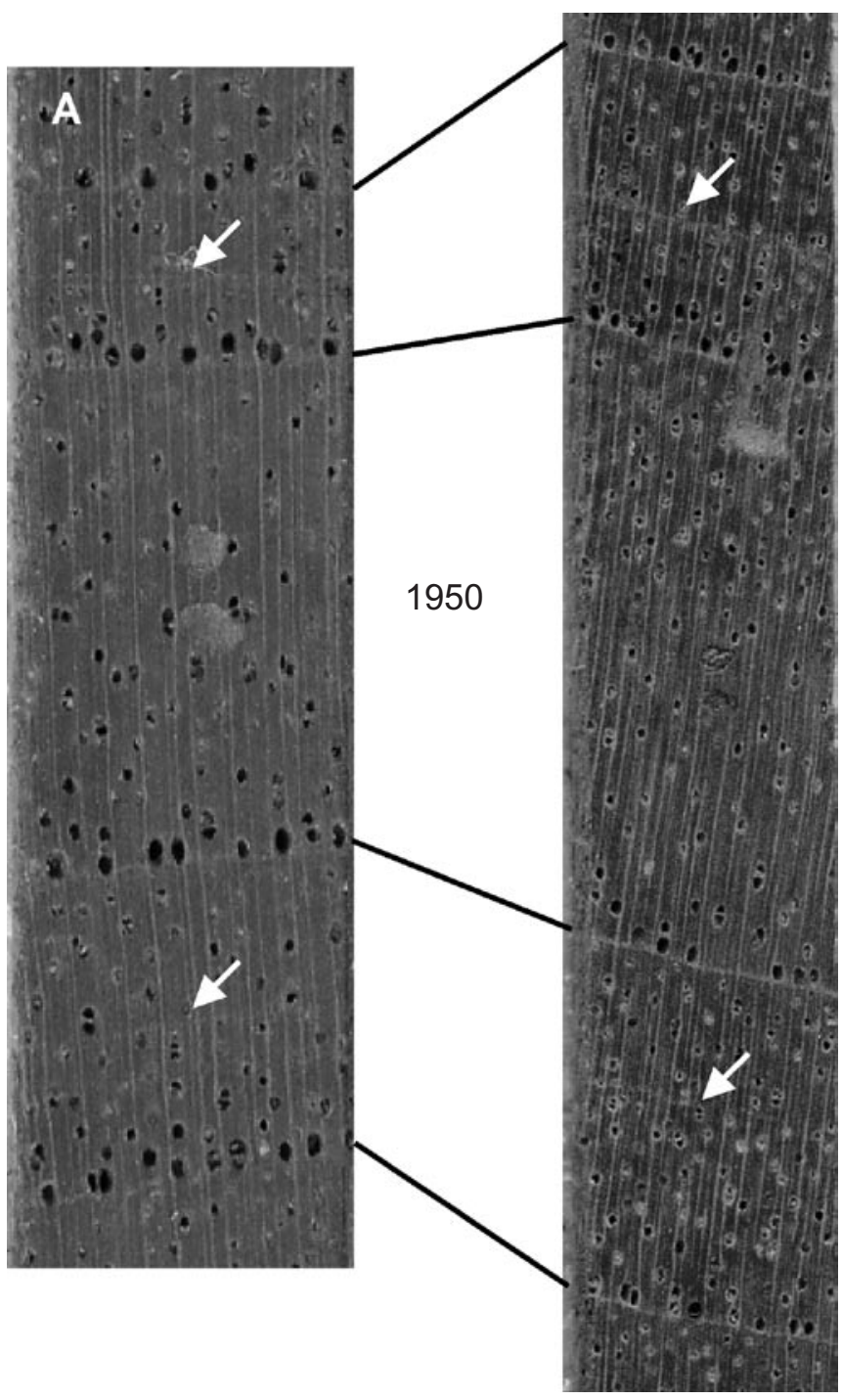

Fig. 12. Detailed view of box A indicated in Fig. 11; crossdating of samples 123a (left) and 123b (right) has identified two false rings adjacent to 1950 indicated by white arrows. 


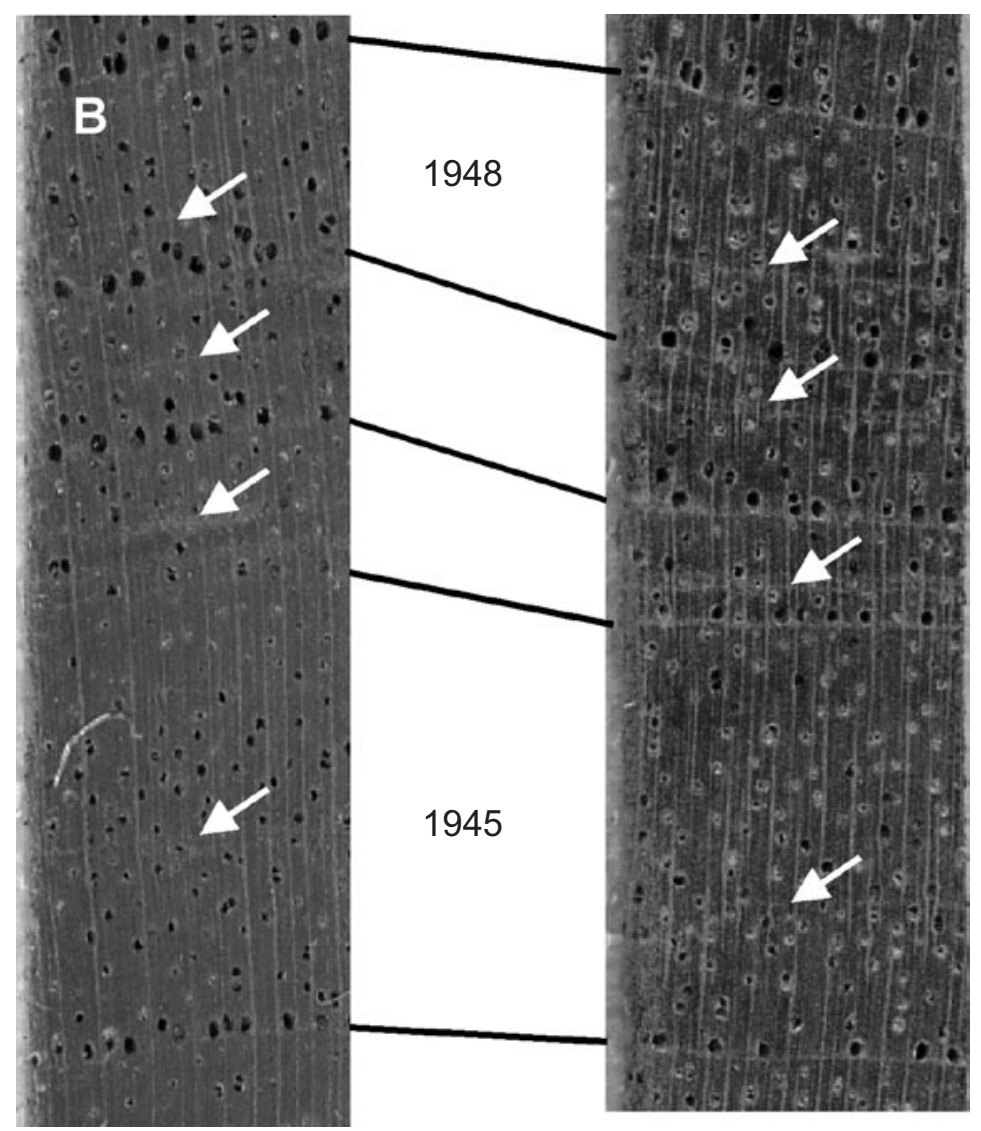

Fig. 13. Detailed view of box B indicated in Fig. 11; crossdating of samples 123a (left) and 123b (right) has identified several false rings indicated by white arrows.

The direct comparison of two core samples (Fig. 11) shows rings generally smaller in core 123a, large annual variations in both samples and contradicting ring widths in some years. It is also remarkable that false rings have mainly been identified in the part of the samples formed as the trees grow older. Several pointer years are visible: very narrow rings between 1992 and 1995 and wider rings between 1980 and 1990 .

In boxes A (Fig. 12) and B (Fig. 13) corresponding sections of the samples have been magnified. They reveal that false rings occur frequently during the 1940s and 1950s. In both samples the year 1950 has been identified as a relatively wide ring which is bordered by rings displaying false rings (white arrows) discernible as weak lines of parenchyma. The annual ring boundaries connected are more distinct because they have bands of prominent parenchyma cells and large earlywood vessels. In box B (Fig. 13), all years contain potential false rings (white arrows) consisting of weak parenchyma bands. After the deletion of the false rings the ring-width variations increase, that is, wider rings 

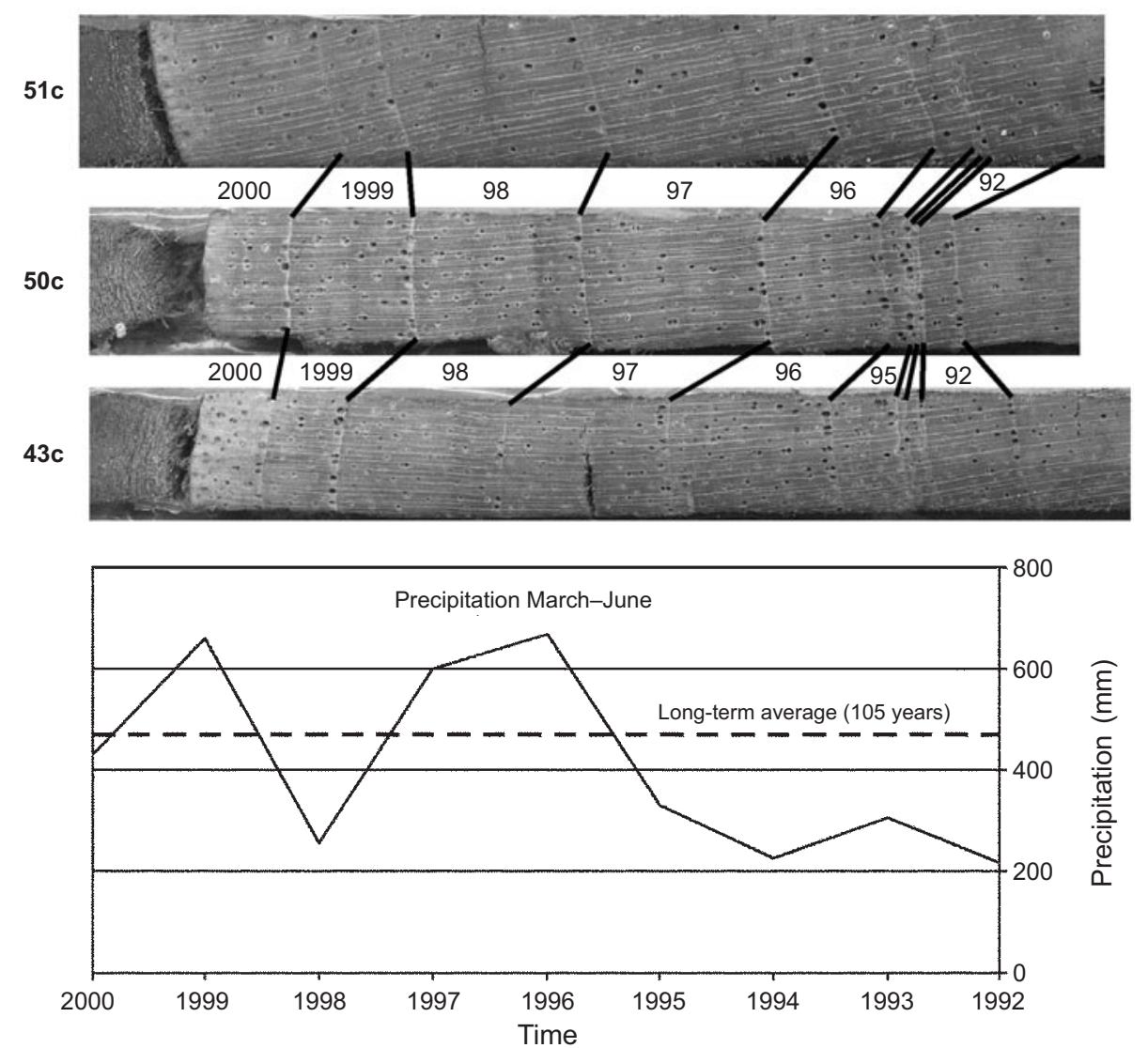

Fig. 14. Visual crossdating of samples 51c, 50c and 43c and comparison with March to June precipitation.

of 1945 and 1948 enclose smaller rings formed in 1946 to 1947. Furthermore, since corresponding false rings occur in both samples they can often act as markers during crossdating as shown in Figures 12 and 13.

Thus far, crossdating within one individual tree has been illustrated. In Figure 14, the next step is taken by comparing samples from different trees. For this purpose years 2000 to 1992 of core samples from three different trees growing on the Atherton Tablelands in tropical Far North Queensland are displayed. The vegetation period starts in September of the previous year and ends in July of the current year, i.e., tree ring 2000 started to grow in 1999 and ended in 2000. For direct comparison March to June precipitation for the corresponding time period is shown as well. The ring boundaries identified in each sample have been connected with lines and the years noted between them. In all samples, large growth variations are apparent, that is, increments between 1995 and 1992 are very small compared to very large rings in 1997 and 1998. Seasonal precipitation data from the Atherton Tablelands are below the long-term average $(469 \mathrm{~mm})$ in 
2000, 1998 and between 1995 and 1992. The periods of below average rainfall obviously had a distinctly negative effect on increment growth, especially during the long drought period 1995 and 1992. The comparison of the samples also demonstrates that some narrow rings, in contrast to many narrow rings (compare Fig. 2), have the potential to improve crossdating results because they are found in most samples and thus can act as pointer years.

\section{DISCUSSION}

The trees in optimum group A did not enter a leafless or semi-leafless period. As a result they did not enter dormancy and hence did not form a ring boundary at all. This strongly suggests that leaf flushes without a period of deciduousness in between are not sufficient to induce tree-ring boundary formation because the cambium does not necessarily become dormant between periods of leaf flushes. For example, the trees in the shading experiment produced multiple leaf flushes without forming even one ring boundary. This confirms results by Tomlinson and Craighead (1972) and Chowdhury (1958). They also found that the number of tree rings was much smaller than the number of leaf flushes.

The examination of wood anatomical anomalies of new T. ciliata material from the tropics and subtropics has helped to identify tree-ring characteristics that hold the potential to hinder or stall crossdating. While a zone of only a few narrow rings can assist crossdating, too many narrow rings usually prevent it. Two problems arise in these zones of narrow rings: first individual tree rings are hard to separate and secondly they prevent a clear differentiation between true and potentially false rings. In extreme cases, when zones of narrow rings are too abundant, reliable crossdating is impossible. In addition, several samples showed very indistinct ring boundaries. Both problems usually necessitate the exclusion of the material affected.

In contrast to results based on the samples from New South Wales (Heinrich \& Banks 2005), the new material from subtropical to tropical northeast Australia exhibited several false rings. They can occur in three qualities, that is, a density variation of the fibre cells only, a density variation of the fibre cells in combination with a line of parenchyma cells, and a line of small vessels that do not change in size distinctly but are embedded in parenchyma cells. This third version of a potential false ring is the most difficult one to expose because it almost fulfils all criteria for a true annual ring.

Growth experiments were conducted to examine whether the periodicity of trees, their growth and wood anatomy can be altered by artificial environmental changes. Only the total defoliation treatment was able to induce a false ring. The false rings formed were of the third version. The vessel sizes did not change distinctly and the vessels were embedded in a line of parenchyma. However, Coster (1928) found that after defoliation, either by hand or due to prolonged dry conditions, trees formed a false ring that was characterised by a row of vessels not surrounded by parenchyma. Furthermore, in the partial defoliation experiment he also discovered false rings; however, these were less distinct compared to those of the total defoliation group. As a visible result of the minimum water treatment in group B of the current trial the trees shed some of their leaves due to strong wilting. Conversely, this partial defoliation did not result in the 
formation of a false ring in this study. While the current results suggest that false rings are only formed after total defoliation Coster's (1928) study implies their occurrence even after a partial loss of foliage. These differences between the current and Coster's results are difficult to explain but might be due to variations in the experimental conductance and the sample material, e.g., Coster (1928) partly defoliated the trees by hand but in the current experiment the partial defoliation was a response to the imposed drought stress. Further experiments with diverse degrees of defoliation need to be conducted in order to fully understand the different growth responses of T. ciliata.

Coster (1928) concluded that it would be impossible to artificially create a false ring, which would be indistinguishable from an annual tree ring. He proposed that, due to the close relationship between the status of the foliage and the cambium activity, radial growth will cease immediately once the tree has been defoliated. The cambium will not gradually go into dormancy and the resulting last fibre cells produced will not be of the latewood style consisting of thick walls and decreased volume, which is commonly regarded as normal for the end of the growing season. Similarly, the vessels produced after the tree has flushed its leaves will not be of a different size (Coster 1928).

According to Fink (1982), the line of initial parenchyma cells in semi-deciduous to deciduous tropical trees is usually formed in the early season. Then the starch stored in the ray parenchyma cells is mobilised and transported into the newly built tangential parenchyma accompanying the large earlywood vessels. Fink suggests that a false ring would show a lack of parenchyma cells because the tree would not gradually go into dormancy nor be enabled to recycle the nutrients and carbohydrates from the leaves and store them in the ray cells for next season's growth. However, Bhattacharyya et al. (1992) concluded in agreement with the current study that a typical false ring of Toona ciliata is characterised by a row of vessels not changing in size distinctly embedded in a line of parenchyma cells. Apart from these differences in the literature, so far all studies confirmed that false rings might occur in T. ciliata, and that they can be induced artificially.

Nevertheless, in the current study, treatments using minimum water and shading did not result in false ring formation. The minimum water treatment was probably applied for a period too short for a sufficient loss of the foliage to induce a false ring. An additional effect of the shading experiment was the distinct increased height and decreased diameter growth, comparable to the result reported by Gopikumur and Bindu (1999).

It is questionable whether the conclusions can be generalised and applied to adult specimens because the experiment was conducted with young trees. Coster (1928), Chowdhury (1961), Tomlinson and Longman (1981) and Fahn et al. (1981) found that younger tropical trees have less distinct periodic growth patterns and that they continuously develop new shoots under good growing conditions, thereby keeping up plant hormone levels, which inhibit the cambium from going into dormancy and finally result in indistinct ring patterns. This phenomenon was also encountered in the present study; therefore, during tree-ring analysis young material of tropical trees such as Toona ciliata should be handled with care. However, the same authors also observed that false rings in older trees were less common, which was confirmed in this study as well. Most of the false rings were identified within the inner younger part of the core 
samples analysed. This suggests that false rings probably only occur in adult specimens under very extreme conditions, such as total defoliation during a direct cyclone hit or a very extreme drought followed by a fire entering the rainforest, as suggested by Herwitz et al. (1998).

Under shady conditions which occur during monsoonal troughs and tropical cyclones in northeast Australia mature trees are likely to produce new shoots and leaves to compensate the low levels of available sun light but will not increase height growth. Although large trees can generally store more energy reserves, and hence compensate more efficiently during temporarily restricting growth conditions they might still be forced to reduce their diameter growth if storages were declining which would suggest that prolonged periods of heavy shade could negatively affect diameter growth of T. ciliata.

Despite the difficulties mentioned it has been shown that it is possible to crossdate Toona ciliata samples from the tropics and subtropics. Zones of only a few narrow rings or other distinct features such as density fluctuations and even false rings can be used as pointers. The fact that three samples from different trees were crossdated visually, and showed a positive relationship to seasonal precipitation data, is a strong indication that the species forms mainly annual tree rings which exhibit a common sensitivity to climate parameters.

\section{ACKNOWLEDGEMENTS}

The authors would like to thank "Lui" Ljube Cvetkoski and Luke Wensing of the School of Botany and Zoology, Australian National University for their big support during the growth experiments and the Electron Microscopy Unit of the Australian National University for permission to use its facilities. Ingo Heinrich gratefully received $\mathrm{PhD}$ scholarships from the Australian National University, the CRC for Greenhouse Accounting and the German Academic Exchange Service (DAAD).

\section{REFERENCES}

Amobi, C.C. 1974. Periodicity of wood formation in twigs of some tropical trees in Nigeria. Annals of Botany 38: 931-936.

Banks, J.C.G. 1993. Tree-ring analysis of two mountain ash trees, Eucalyptus regnans F. Muell. from the Watts and O'Shannassy catchments, Central Highlands, Victoria: a report to the Central Highlands Old Growth Forest project. Australian National University, Canberra.

Bauch, J. \& O. Dünisch. 2000. Comparison of growth dynamics and wood characteristics of plantation-grown and primary forest Carapa guianensis in Central Amazonia. IAWA J. 21: 321-333.

Bhattacharyya, A., R.R. Yadav, H.P. Borgaonkar \& G.B. Pant. 1992. Growth-ring analysis of Indian tropical trees - Dendroclimatic potential. Curr. Sci. 62: 736-741.

Bowers, N.A. 1964. New method of surfacing wood specimens for study. Tree-Ring Bull. 26: $2-5$.

Chowdhury, K.A. 1958. Extension and radial growth in tropical perennial plants. In: P. Maheshwari (ed.), Modern developments in plant physiology: 10-20. Delhi University, Delhi, India.

Chowdhury, K.A. 1961. Growth rings in tropical trees and taxonomy, Abstract 280. 10th Pacific Science Congress. Pacific Science Association, Honolulu.

Cook, E.R. \& L.A. Kairiukstis. 1990. Methods of dendrochronology. Applications in the environmental sciences. Kluwer Academic Pub., Dordrecht, Netherlands. 
Coster, C. 1928. Zur Anatomie und Physiologie der Zuwachszonen- und Jahresringbildung in den Tropen. II. Ann. Jard. Bot. Buitenzorg 38: 1-114.

Doley, D. 1979. Effects of shade on xylem development in seedlings of Eucalyptus grandis Hill ex Maiden. The New Phytologist 82: 545-555.

Fahn, A., J. Burley, K. A. Longman, A. Mariaux \& P.B. Tomlinson. 1981. Possible contributions of wood anatomy to the determination of the age of tropical trees. In: F.H.B. Bormann \& G. Berlyn (eds.), Age and growth rate of tropical trees: new directions for research. Proceedings of the workshop on age and growth rate determination for tropical trees: 31-54. Yale University, New Haven.

Fink, S. 1982. Histochemical investigations on starch-distribution and activity of acid-phosphatases in the xylem of some tropical tree species. Holzforschung 36: 295-302.

Fritts, H.C. 1976. Tree rings and climate. Blackburn Press, Caldwell, New Jersey.

Fujii, T., A.T. Salang \& T. Fujiwara. 1999. Growth periodicity in relation to the xylem development in three Shorea spp. (Dipterocarpaceae) growing in Sarawak. In: R.V. Wimmer \& R. Vetter (eds.), Tree ring analysis. Biological, methodological and environmental aspects: 131-137. CAB International, New York.

Gopikumur, K. \& S. Bindu. 1999. Effect of shade on the growth of selected tropical forest tree species under nursery condition. J Trop. For. Sci. 11: 651-653.

Heady, R.D. 1997. The wood anatomy of Callitris Vent. (Cupressaceae): an SEM study. Australian National University, Canberra.

Heinrich, I. \& J.C.G. Banks. 2005. Dendroclimatological potential of the Australian red cedar. Austr. J. Bot. 53: 21-32.

Herwitz, S.R., R.E. Slye \& S.M. Turton. 1998. Redefining the ecological niche of a tropical rain forest canopy tree species using airborne imagery: long-term crown dynamics of Toona ciliata. J. Trop. Ecol. 14: 683-703.

Kuroda, K. 1986. Wound effects on cytodifferentiation in the secondary xylem of woody plants. Wood Research 72: 67-118.

Kuroda, K. \& K. Shimaji. 1984. The pinning method for marking xylem growth in hardwood species. Forest Science 30: 548-554.

Kuroda, K. \& K. Shimaji. 1985. Wound effects on cytodifferentiation in hardwood xylem. IAWA Bull. n.s. 6: 107-118.

Mariaux, A. 1967. Les cernes dans les bois tropicaux Africans nature et périodicité. Rev. Bois et Forêts Trop. 114: 23-37.

Nobuchi, T., Y. Ogata \& S. Siripatanadilok. 1995. Seasonal characteristics of wood formation in Hopea odorata and Shorea henryana. IAWA J. 16: 361-369.

Pilcher, J.R. 1990. Sample preparation, cross-dating, and measurement. In: E.R. Cook \& L.A. Kairiukstis (eds.), Methods of dendrochronology. Applications in the environmental sciences: 40-51. Kluwer Academic Pub., Dordrecht, Netherlands.

Sass, U., W. Killmann \& D. Eckstein. 1995. Wood formation in two species of Dipterocarpaceae in Peninsular Malaysia. IAWA J. 16: 371-384.

Schweingruber, F.H. 1983. Der Jahrring. Standort, Methodik, Zeit und Klima in der Dendrochronologie. Haupt Verlag, Bern, Stuttgart.

Shiokura, T. 1989. A method to measure radial increment in tropical trees. IAWA Bull. n.s. 10: $147-154$.

Stokes, M.A. \& T.L. Smiley. 1968. An introduction to tree ring dating. University of Chicago Press, Chicago.

Tomlinson, P.B. \& F.C.S. Craighead. 1972. Growth-ring studies on the native trees of subtropical Florida. In: A.K.M. Ghouse \& M. Yunus (eds.), Research trends in plant anatomy: 39-51. Tata McGraw-Hill, New Delhi, India. 
Tomlinson, P.B. \& K.A. Longman. 1981. Growth phenology of tropical trees in relation to cambial activity. In: F.H.B. Bormann \& G. Berlyn (eds.), Age and growth rate of tropical trees: new directions for research. Proceedings of the workshop on age and growth rate determination for tropical trees: 7-19. Yale University, New Haven.

Unwin, G.L., G.B. Applegate, G.C. Stocker \& D.I. Nicholson. 1988. Initial effects of tropical cyclone "Winifred" on forests in north Queensland. In: R.L. Kitching (ed.), Proceedings of the Ecological Society of Australia: 282-296. Chipping Norton.

Webb, L.J. 1958. Cyclones as an ecological factor in tropical lowland rainforest, North Queensland. Austrl J. Bot. 6: 220-228.

Webb, L.J. 1959. A physiognomic classification of Australian rain forests. J. Ecology 47: 551570.

Wolter, K.E. 1968. A new method for marking xylem growth. Forest Science 14: 102-104. 